\section{Third Party Administrator}

\section{Glenn S. Ashkanazi}

Department of Clinical and Health Psychology, University of Florida-College of Public Health and Health Professions, Gainesville, FL, USA

\section{Definition}

Typically, an independent organization that provides administrative services for an insurance company, self-insured employer or may also operate as a unit of an insurance company. These services may include claims administration (processing, adjudication and negotiation of claims), managing provider networks, conducting utilization review, membership functions (e.g. verifying member eligibility), recordkeeping and authorizing benefits. The risk of financial loss remains with the insurer, or employer, and not the TPA. Third Party Administrators have the expertise to manage other functions including premium collection and member enrollment.

\section{Cross-References}

Case Management 